\title{
Fuzzy Inference System for an Integrated Knowledge Management System
}

\author{
S. Maria Wenisch \\ Department of Information Science \\ and Technology \\ Anna University \\ Chennai - 600025
}

\author{
G.V. Uma \\ Department of Information Science \\ and Technology \\ Anna University \\ Chennai - 600025
}

\author{
A. Ramachandran \\ Center for Climate Change and \\ Adaptation Research \\ Anna University \\ Chennai - 600025
}

\begin{abstract}
An integrated and holistic approach to knowledge management system for natural resource management needs to take local indigenous knowledge as one of its components for achieving sustainability. The system of indigenous or local ecological knowledge on natural resource is fuzzy. The integration of such fuzzy knowledge requires a methodology for converting fuzzy data into crisp data for a quantitative analysis. The process of arriving at a conclusion from indigenous knowledge fuzzy data is done using a set of fuzzy inference rules. This work shows that fuzzy inference system is an efficient method to demonstrate defuzzification of the local ecological knowledge using fuzzy inference process. The paper builds a fuzzy inference system from the fuzzy indigenous knowledge system on soil. The inference rules are framed from the fuzzy indigenous knowledge on soil as IF...THEN structures. FIS tool in Matlab is used for building a mamdani fuzzy inference system using the inferences. The relationships between various factors influencing the suitability of soil for crops are produced as the output of the suitability fuzzy inference system.
\end{abstract}

\section{General Terms}

Artificial Intelligence, Expert System, Fuzzy Inference System, Knowledge Management System

\section{Keywords}

Local Knowledge, Fuzzy Knowledge, Fuzzy Inference System, Defuzzification, Suitability Analysis, Sustainability.

\section{INTRODUCTION}

Sustainability is a major aim and concern of a natural resource management system. Local indigenous knowledge has been identified as a major contributor towards achieving sustainable management of natural resource. Indigenous knowledge system of managing natural resource is a fuzzy system. The fuzziness of indigenous knowledge is attributed to the experience gained out of the proximity of the knower with nature. The indigenous communities use qualitative terms to describe their data. One of the methods to combine indigenous qualitative data with scientific quantitative data is to defuzzify the indigenous qualitative data that can be ultimately combined with quantitative non-fuzzy data for analysis of the experts on sustainability. Researchers have explored such fuzzy knowledge systems and have proposed various methods for better analysis and understanding. A.Xing et al [1] have constructed fuzzy membership functions for descriptive knowledge in order to explore the relationships in soil mapping. They have explored knowledge on typical environmental conditions on each soil type and on correspondence between soil types and changes in environmental conditions. The authors have also suggested that a descriptive knowledge obtained from other sources could be used to construct membership functions. Using weighted fuzzy association rules Yue-Ju Xue et al [2] have mined regional soil quality as a prior knowledge for land planning and utilization. A-Xing Zhu et al [3] have proposed and used three approaches that use soil fuzzy membership values to predict detailed spatial variation of soil properties. Uncertainties in expert knowledge have been represented using fuzzy variables and inference rules by Janssen et al [4]. Mohammed H. Vahidnia et al [5] have manipulated fuzzy inference system (FIS) and ANN to assess landslides. Integration of local and technical knowledge to support salinity monitoring has been done by Giordano et al [6]. Milos Kovacevic et al [7] have worked on SVM in the estimate of values of soil properties and soil type classification based on known values of particular chemical and physical properties in sampled profiles. Fuzzy knowledge present in indigenous knowledge on ecology is well explored by Fikret Berkes et al [8].

For local knowledge to be used in natural resource management there is a requirement for effective methods for acquiring and evaluating it. One of the methods is to enable explicit representation of local knowledge by using a knowledge based systems approach. This methodology formally represents qualitative knowledge on computer. It is based on the premise that most knowledge can be broken down into short statements and associated taxonomies of the terms that are used in them. These unitary statements and associated taxonomies can then be represented on a computer as a knowledge base using a formal grammar and a series of hierarchies of terms. Connections amongst statements can be explored by viewing sets of related statements as diagrams. The formalization of knowledge in this way also makes it possible for the use of automated reasoning procedures to help evaluate and explore complex knowledge domains.

\section{MATERIAL AND METHODS}

\subsection{Material}

This work uses the secondary fuzzy data of local indigenous knowledge on soil of Sumberjaya, Indonesia collected by Laxman Joshi and Elok Mulyotami using AKT5 (Agro-ecological Knowledge Toolkit). From the indigenous data on soil collected from the farmers and other secondary sources, a knowledge base on soil is created using AKT5, a software tool designed by Bangor 
University. The properties of soil like colour, structure are taken for the study. The tables and can be used as a simple knowledge base that stores the properties colour, organic matter content, nutrient content, iron content, fertility, structure and the location of soil. From the knowledge available rules are framed for the suitability for crops. This study has taken only some properties of black soil and red soil into account for its design and analysis of FIS

\section{Table 1. Farmers' Knowledge collected by Laxman Joshi and} Elok Mulyotami

\begin{tabular}{|c|c|c|c|}
\hline Type of Soil & $\begin{array}{c}\text { Black } \\
\text { Soil }\end{array}$ & Red Soil & Yellow Soil \\
\hline Colour & Black & Red/Yellowish & Yellow \\
\hline $\begin{array}{c}\text { Organic } \\
\text { matter } \\
\text { content }\end{array}$ & High & Average & Low \\
\hline $\begin{array}{c}\text { Nutrient } \\
\text { content }\end{array}$ & High & Average & Low \\
\hline Iron Content & Low & High & High \\
\hline Fertility & High & Average & Low \\
\hline Location & $\begin{array}{c}\text { Surface(t } \\
\text { op soil) }\end{array}$ & $\begin{array}{c}\text { Second } \\
\text { layer(sub soil) }\end{array}$ & Sub soil \\
\hline
\end{tabular}

Table 2. Farmers' Knowledge on black soil and red soil collected by Laxman Joshi and Elok Mulyotami

\begin{tabular}{|l|l|l|l|l|l|l|}
\hline $\begin{array}{l}\text { Type } \\
\text { of Soil }\end{array}$ & $\begin{array}{l}\text { Struct } \\
\text { ure }\end{array}$ & $\begin{array}{l}\text { Suitabi } \\
\text { lity } \\
\text { for } \\
\text { coffee }\end{array}$ & $\begin{array}{l}\text { Suitabi } \\
\text { lity } \\
\text { for } \\
\text { paddy }\end{array}$ & $\begin{array}{l}\text { Paddy } \\
\text { Rice } \\
\text { taste }\end{array}$ & $\begin{array}{l}\text { Eroda } \\
\text { bility }\end{array}$ & $\begin{array}{l}\text { Fertiliz } \\
\text { er } \\
\text { Requir } \\
\text { ement }\end{array}$ \\
\hline \multirow{2}{*}{$\begin{array}{l}\text { Black } \\
\text { Soil }\end{array}$} & Loose & $* * *$ & $* * *$ & $* *$ & $* * *$ & $*$ \\
\cline { 2 - 6 } & Sandy & $* *$ & $* *$ & & $*$ & $* *$ \\
\cline { 2 - 6 } & $\begin{array}{l}\text { Hard/St } \\
\text { icky }\end{array}$ & $*$ & $*$ & & $*$ & $* *$ \\
\hline \multirow{2}{*}{$\begin{array}{l}\text { Red } \\
\text { Soil }\end{array}$} & Loose & $* *$ & $* * *$ & $* * *$ & $* * *$ & $* *$ \\
\cline { 2 - 6 } & Sandy & $*$ & $* *$ & & $* *$ & $* *$ \\
\cline { 2 - 6 } & $\begin{array}{l}\text { Hard/St } \\
\text { icky }\end{array}$ & $*$ & $*$ & & $*$ & $* * *$ \\
\hline
\end{tabular}

Note: *** high, ** medium, * low

\subsection{Methods}

\subsubsection{AKT5 Knowledge Base System}

AKT5 is described as Agroecological Knowledge toolkit (AKT5) software developed by the University of Wales, Bangor, in conjunction with the Department of Artificial Intelligence at Edinburgh University. It was designed to provide an environment for knowledge acquisition in order to create knowledge bases from a range of sources. It allows representation of knowledge elicited from farmers and scientists or knowledge abstracted from written material. The use of formal knowledge representation procedures offers researchers the ability to evaluate and utilize the often complex, qualitative information relevant stakeholders has on agroecological practices. The methodology associated with knowledge elicitation for the AKT5 system allows for formalized flexible knowledge bases to be created. Essentially during knowledge base creation, knowledge is elicited through a process of semi-structured interviews with key informants. This knowledge is then broken down into unitary statements, and represented using a formal grammar, in either a statement or diagrammatic format. The process of representation requires iterative evaluation of the knowledge as it is inputted and therefore provides the basis for further questioning; the process of elicitation continues until no further knowledge is available. This process permits very robust knowledge bases on specified topics to be created. This allows for a system where the knowledge is stored in a form that is comprehensive, accessible and easily updateable. The system also allows knowledge bases developed from distinct sources to be compared through the use of automated reasoning tools, and thus provides a flexible research resource. This allows local and scientific knowledge to be compared and evaluated.

\subsubsection{Inference Rules}

The inference rules are of the form IF condition, THEN consequent. The conditions and the consequent both can have multiple values conjunct by $A N D$ operator or disjunct by $O R$ operator. The knowledge from the table 1 is given as IF....THEN else statements in equations 1,2 , and 3 .

IF (type of soil $=$ black soil) THEN $($ colour $=$ black

$\wedge$ organic matter content $=$ high

$\wedge^{\wedge}$ nutrient content $=$ high

$\wedge$ iron content $=$ low

${ }^{\wedge}$ fertility $=$ high

^location $=$ top)

IF (type of soil $=$ red soil) THEN $($ colour $=$ red

yellowish

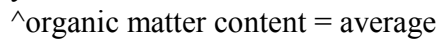

$\wedge$ nutrient content $=$ average

$\wedge$ iron content $=$ high

$\wedge$ fertility $=$ average

$\wedge$ location $=$ sub soil $)$

IF (type of soil $=$ yellow soil) THEN $($ colour $=$ yellow

$\wedge$ organic matter content $=$ low

$\wedge^{\wedge}$ nutrient content $=$ low

$\wedge$ iron content $=$ high

$\wedge^{\wedge}$ fertility $=$ low

$\wedge$ location $=$ sub soil)

The knowledge from the table 2 form $\boldsymbol{I F}$.... THEN else statements in equations $4,5,6,7,8$, and 9 .

IF (type of soil $=$ black $^{\wedge}$ structure $=$ loose) THEN

(Suitability for coffee $=$ high

${ }^{\wedge}$ suitability for paddy $=$ high

${ }^{\wedge}$ paddy rice taste $=$ medium

$\wedge$ erodability $=$ high

$\wedge$ fertilizer requirement $=$ low)

IF (type of soil $=$ black $^{\wedge}$ structure $=$ sandy) THEN

(Suitability for coffee $=$ medium

$\wedge^{\wedge}$ suitability for paddy $=$ medium

$\wedge$ erodability $=$ low

$\wedge$ fertilizer requirement $=$ medium)

IF $\left(\right.$ type of soil $=$ black $^{\wedge}$ structure $=$ hard _ sticky $)$

THEN

(Suitability for coffee $=$ low

${ }^{\wedge}$ suitability for paddy $=$ low

$\wedge$ erodability $=$ low

$\wedge$ fertilizer requirement $=$ medium $)$ 
IF (type of soil $=$ red $^{\wedge}$ structure $=$ loose) THEN

(Suitability for coffee $=$ medium

$\wedge^{\wedge}$ suitability for paddy $=$ high

$\wedge$ paddy rice taste $=$ high

$\wedge$ erodability $=$ high

$\wedge$ fertilizer requirement $=$ medium)

IF (type of soil $=$ red $^{\wedge}$ structure $=$ sandy) THEN

(Suitability for coffee $=$ low

$\wedge$ suitability for paddy $=$ medium

$\wedge$ erodability $=$ medium

$\wedge$ fertilizer requirement $=$ medium $)$

IF (type of soil $=\operatorname{red}^{\wedge}$ structure $=$ hard $\_$sticky) THEN

(Suitability for coffee $=$ low

$\wedge$ suitability for paddy $=$ low

$\wedge$ erodability $=$ low

$\wedge$ fertilizer requirement $=$ high)

From the equations 1, 2, and 3 we can form a generalized IF....THEN else statement in the following way.

IF $\left(\right.$ type of soil $\left.=\mathrm{x}_{1}\right)$ THEN $\left(\right.$ colour $=\mathrm{y}_{1}$

$\wedge$ organic matter content $=\mathrm{y}_{2}$

$\wedge$ nutrient content $=\mathrm{y}_{3}$

$\wedge$ iron content $=\mathrm{y}_{4}$

$\wedge$ fertility $=\mathrm{y}_{5}$

^location $=\mathrm{y}_{6}$ )

Where, $\mathrm{x}_{1}, \mathrm{y}_{1}, \mathrm{y}_{2}, \mathrm{y}_{3}, \mathrm{y}_{4}, \mathrm{y}_{5}$ and, $\mathrm{y}_{6}$ are fuzzy variables. For example, $\mathrm{x}_{1}$ can be black or red or yellow and $\mathrm{y}_{2}$ may have values like high, average or low.

From the equations 4 to 10 we form $\boldsymbol{I F}$.... THEN else statements of the form IF condition AND condition THEN consequent.

IF (type of soil $=\mathrm{x}_{1} \wedge$ structure $=\mathrm{x}_{2}$ ) THEN

(Suitability for coffee $=z_{1}$

$\wedge^{\wedge}$ suitability for paddy $=z_{2}$

$\wedge$ paddy rice taste $=z_{3}$

$\wedge$ erodability $=\mathrm{z}_{4}$

$\wedge^{\wedge}$ fertilizer requirement $=z_{5}$ )

Where, $x_{1}, x_{2}, z_{1}, z_{2}, z_{3, z}$ and $z_{5}$ are fuzzy variables. For example, $\mathrm{x}_{2}$ can be loose or sandy or hard and $\mathrm{z}_{2}$ may have values like high, medium or low.

\subsection{Fuzzy Inference System}

A typical fuzzy inference system (see Figure 1) has the following components:

- Crisp input

- Fuzzification Interface

- $\quad$ Fuzzy Inference Engine

- Defuzzification

Fuzzy Set Data

- Fuzzy Rule Base

- $\quad$ Crisp Output

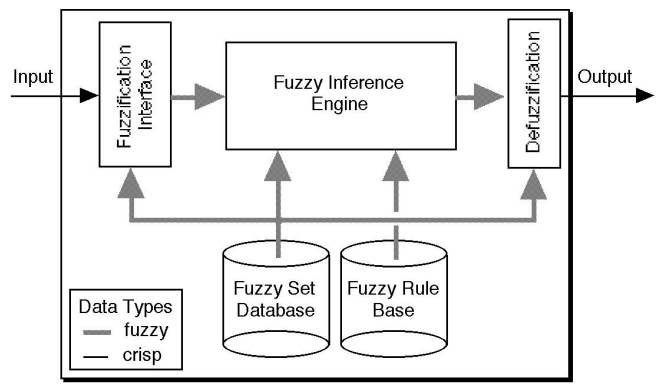

Figure 1. A Typical Fuzzy Inference System

From the equations 1 to 9 a mamdani fuzzy inference system using FIS tool in Matlab 6.5 has been simulated with 6 inference rules (see Figure 2), two input variables, and 5 output variables. The type of soil and the structure of the soil are given as the input to the FIS while suitability for coffee, suitability for paddy, paddy taste, erodability, and fertilizer requirement are the outputs of FIS.

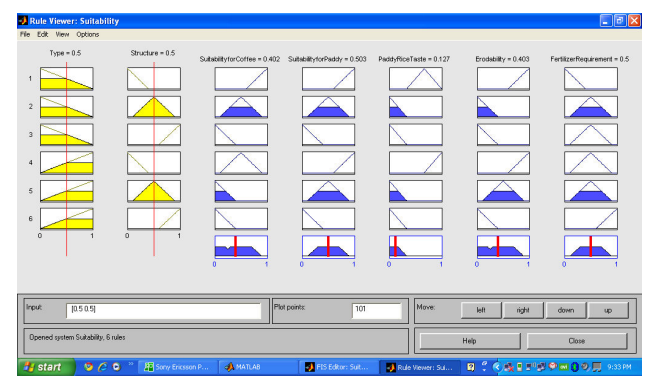

Figure 2. Fuzzy Inference Rules

Steps that we have followed for building the Fuzzy Inference System from AKT5 data are:

- Knowledge Acquisition

- AKT5 Tool use

- Knowledge Base Creation

- Inference Rules Formation

- $\quad$ FIS Design

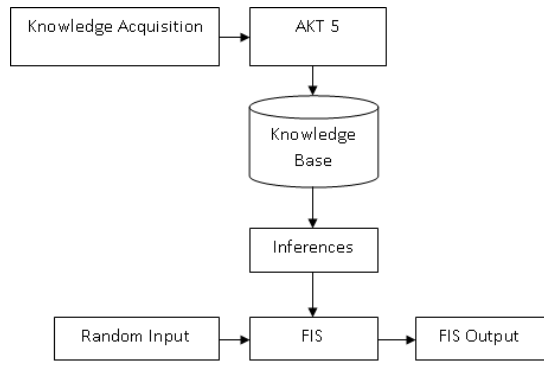

Figure 3. The Processes for building FIS from AKT5 KB

\section{RESULT AND DISCUSSION}

For the two inputs, type and structure membership functions have been built (see Figure 4). A range from 0 to 1 has been assigned for the types 'black' and 'red'. Structure has three membership functions such as loose, sandy, sticky or hard. Similarly the membership functions for outputs such as suitability coffee, suitability paddy, paddy rice taste, erodability, and fertilizer requirement are also plotted. The appendix presents the 
membership functions for the inputs and outputs(see Figure 5), the two dimensional plots that show the relationships between type and suitability for coffee, type and suitability for paddy, type and paddy rice taste, type and fertilizer utilization, and type and erodability (figure 7). Similarly the relationships between structure and suitability for coffee, structure and suitability for paddy, structure and paddy rice taste, structure and fertilizer utilization, and structure and erodability are plotted (figure 6). It is feasible to analyze how the type or structures have effects on these suitability conditions. Analysis combining type and structure with various suitability requirements results in surface plots (figure 8). For example type and structure combined with suitability for coffee crop is represented in a surface plot.

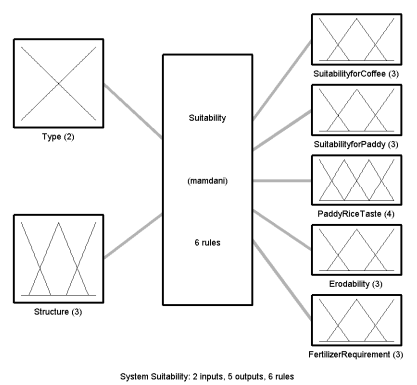

Figure 4. Membership Functions Designed in FIS

Matrix 50x2 random numbers generated using rand function in Matlab are used as input to evaluate (evalfis) the designed fuzzy inference system called Suitability. The fuzzy inference system has produced 50x5 matrix output (Figure 9).

\section{CONCLUSION}

Indigenous knowledge on the type and structure of soil from Sumber, Indonesia collected by Laxman Joshi and Elok Mulyotami using AKT5 was studied. Based on the knowledge on the structure of soil and type, rules were first formed in IF...THEN structure. The inference rules were then used to build a fuzzy inference system (FIS) using FIS tool in Matlab 6.5. Mamdani's fuzzy inference method and centroid method were employed in the fuzzy inference system. The constructed FIS had two inputs, 6 rules and 5 outputs. The relationship between various inputs and the outputs were plotted on two dimensional and three dimensional surfaces for the analysis.

As the enhancement of this work, farmers' knowledge on the various properties of soil which are in fuzzy terms can be analyzed with a similar method. Fuzzy knowledge combined with crisp scientific knowledge for a quantitative understanding and analysis would facilitate a holistic complete knowledge and understanding of natural resource for achieving sustainable management of natural resource. In developing a knowledge management system, AKT5 as a knowledge based system is very much useful and efficient for building a knowledge base of indigenous experts and scientific experts. AKT5 can be combined with any other knowledge management system to design an integrated knowledge management system that would have a holistic approach to natural resource management.

\section{ACKNOWLEDGMENTS}

We owe our sincere thanks to Laxman Joshi and Elok Mulyotami for their knowledge base on Sumber, Indonesia using AKT5.

\section{REFERENCES}

[1] A-Xing Zhu, Lin Yang, Baolin Li, Chengzhi Qin, Tao Pei, Baoyuan Liu, "Construction of membership functions for predictive soil mapping under fuzzy logic", Geoderma, Volume 155, Issues 3-4, 15, March 2010, Pages 164-174.

[2] Yue-Ju XUE, Shu-Guang LIU, Yue-Ming HU, Jing-Feng YANG, "Soil Quality Assessment Using Weighted Fuzzy Association Rules", Pedosphere, Volume 20, Issue 3, June 2010, Pages 334-341.

[3] A-Xing Zhu, Feng Qi, Amanda Moore, James E. Burt, "Prediction of soil properties using fuzzy membership values", Geoderma, In Press, Corrected Proof, Available online 13 June 2010.

[4] J.A.E.B. Janssen, M.S. Krol, R.M.J. Schielen, A.Y. Hoekstra, J.-L. de Kok, "Assessment of uncertainties in expert knowledge, illustrated in fuzzy rule-based models", Ecological Modeling, Volume 221, Issue 9, 10 May 2010, Pages 1245-1251.

[5] Mohammad H. Vahidnia, Ali A. Alesheikh, Abbas Alimohammadi, Farhad Hosseinali, "A GIS-based neurofuzzy procedure for integrating knowledge and data in landslide susceptibility mapping", Computers I\& Geosciences, In Press, Corrected Proof, Available online 30 June 2010 .

[6] R. Giordano, S. Liersch, M. Vurro, D. Hirsch, "Integrating local and technical knowledge to support soil salinity monitoring in the Amudarya river basin", Journal of Environmental Management, Volume 91, Issue 8, August 2010, Pages 1718-1729.

[7] Miloš Kovacevic, Branislav Bajat, Boško Gajic, "Soil type classification and estimation of soil properties using support vector machines", Geoderma, Volume 154, Issues 3-4, 15, January 2010, Pages 340-347.

[8] Fikret Berkes, Mina Kislalioglu Berkes, "Ecological complexity, fuzzy logic, and holism in indigenous knowledge”, Futures, Volume 41, Issue 1, February 2009, Pages 6-12.

[9] Ana C. Meira Castro, Joao Paulo Carvalho, S. Ribeiro, "Prescribed burning impact on forest soil properties-A Fuzzy Boolean Nets approach", Environmental Research, In Press, Corrected Proof, Available online 18, April 2010.

[10] Eva M. López, Miriam García, Marta Schuhmacher, José L. Domingo, "A fuzzy expert system for soil characterization", Environment International, Volume 34, Issue 7, October 2008, Pages 950-958.

[11] Manfred Kaufmann, Silvia Tobias, Rainer Schulin, "Quality evaluation of restored soils with a fuzzy logic expert system", Geoderma, Volume 151, Issues 3-4, 15 July 2009, Pages 290-302.

[12] Rodrigo S. Sicat, Emmanuel John M. Carranza, Uday Bhaskar Nidumolu, "Fuzzy modeling of farmers' knowledge for land suitability classification", Agricultural Systems, Volume 83, Issue 1, January 2005, Pages 49-75. 
[13] T. Rajaram, Ashutosh Das, "Modeling of interactions among sustainability components of an agro-ecosystem using local knowledge through cognitive mapping and fuzzy inference system", Expert Systems with Applications, Volume 37, Issue 2, March 2010, Pages 1734-1744.

\section{APPENDIX}
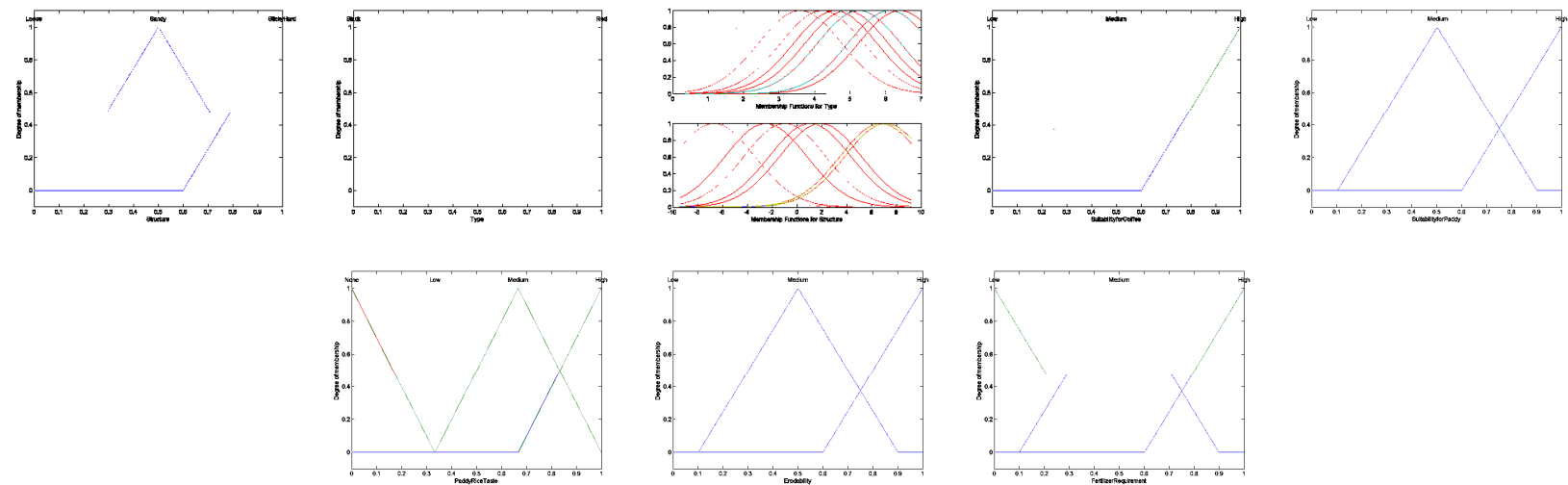

Figure 5. Membership Functions
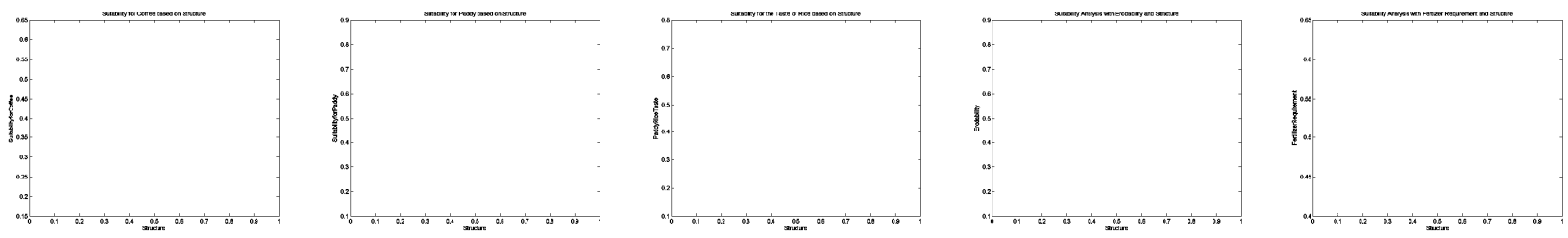

Figure 6. Structure and Suitability Analysis
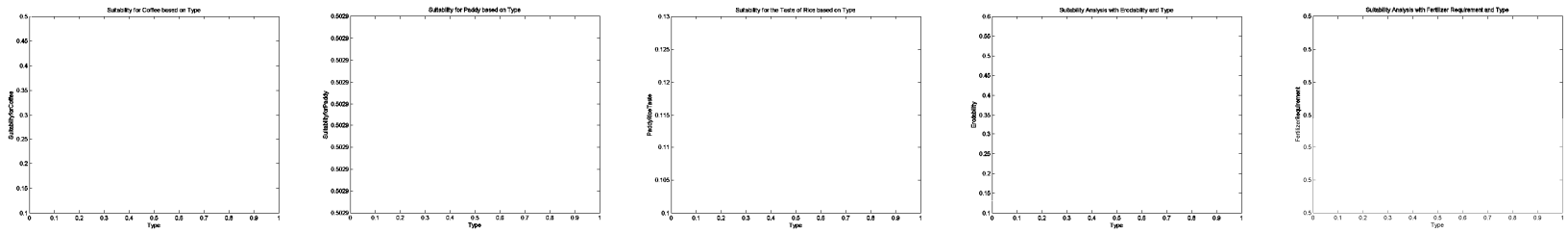

Figure 7. Type and Suitability Analysis
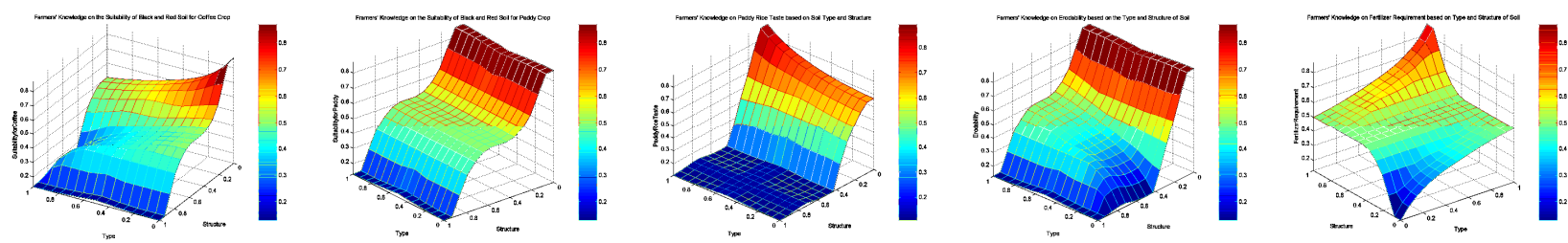

Figure 8. Type and Structure and Suitability
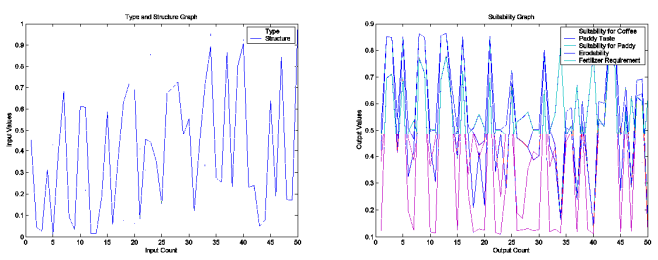

Figure 9. Input and Output Plot of FIS 